\title{
Childhood
}

\section{Navigating babysitting as liminal, gendered, and undervalued work}

\begin{tabular}{|r|l|}
\hline Journal: & Childhood \\
\hline Manuscript ID & CHD-20-0008.R3 \\
\hline Manuscript Type: & Original Manuscript \\
\hline Keywords: & $\begin{array}{l}\text { Babysitting, Young worker, Liminality, Canada, Qualitative Research, } \\
\text { Child Employment }\end{array}$ \\
\hline Abstract: & $\begin{array}{l}\text { Babysitting is a common early-work experience in the West, yet there is } \\
\text { little research on babysitters. From in-depth, qualitative interviews with } \\
\text { in babysitters, we explore three themes related to liminality and gender } \\
\text { babysitters undertook formal and informal training and used it at work. } \\
\text { Second, babysitters occupy a liminal position between childhood and } \\
\text { adulthood, bringing challenges and opportunities at work. Finally, } \\
\text { babysitters thoughtfully negotiate pay, but sometimes experience } \\
\text { challenges doing so. }\end{array}$ \\
\hline
\end{tabular}

\section{SCHOLARONE Manuscripts}


Table 1: Interview participants

\begin{tabular}{|l|l|l|}
\hline City \#1 in Ontario & Age & Work \\
\hline 1) Angela & 15 & Babysitting; ice cream store \\
\hline 2) Michelle & 16 & Babysitting; drug store; fast food \\
\hline 3) Ginger & 16 & Babysitting; studio hand \\
\hline 4) Billy Pilgrim & 14 & Babysitting \\
\hline 5) Taylor & 14 & Babysitting; newspaper delivery \\
\hline 6) Charlotte & 16 & $\begin{array}{l}\text { Babysitting; newspaper delivery; fast } \\
\text { food }\end{array}$ \\
\hline 7) Mariah & 16 & Babysitting; fast food \\
\hline 8) Olivia & 16 & Babysitting; dishwasher; pumpkin patch \\
\hline
\end{tabular}

\begin{tabular}{|l|l|l|}
\hline City \#2 in Ontario & Age & Work \\
\hline 1) Emma & 14 & Babysitting \\
\hline 2) Mia & 14 & Babysitting \\
\hline 3) Patricia & 12 & Babysitting; day camp volunteer \\
\hline 4) Bob & 14 & Babysitting; odd jobs \\
\hline 5) April & 13 & Babysitting \\
\hline 6) Violet & 16 & Babysitting \\
\hline
\end{tabular}

\begin{tabular}{|l|l|l|}
\hline City in British Columbia & Age & Work \\
\hline 1) Rose & 14 & Babysitting; house cleaning \\
\hline 2) Jane & 17 & $\begin{array}{l}\text { Babysitting; lemonade stand; newspaper } \\
\text { delivery; restaurant; unionized retail }\end{array}$ \\
\hline
\end{tabular}




\title{
Navigating babysitting as liminal, gendered, and undervalued work
}

\section{Data Availability Statement}

The authors confirm that the data supporting the findings of this study are available within the article.

Word Count: 6954 words

\begin{abstract}
Babysitting is a common early-work experience in the West, yet there is little research on babysitters. From in-depth, qualitative interviews with 16 babysitters, we explore three themes related to liminality and gender inequality in babysitting. First, babysitting is a skilled job; many babysitters undertook formal and informal training and used it at work. Second, babysitters occupy a liminal position between childhood and adulthood, bringing challenges and opportunities at work. Finally, babysitters thoughtfully negotiate pay, but sometimes experience challenges doing so.
\end{abstract}

Key Words: Babysitting, young worker, liminality, Canada, qualitative research, child employment 


\section{Introduction}

Babysitting is a common early-work experience for many young people in the West. For the purpose of this paper, babysitting is the temporary, somewhat sporadic, paid care for children that are not in your own family. Many young people also provide childcare within their families, or work as nannies. We focus on paid, somewhat sporadic care of non-familial children because our larger project was based on part-time, paid work outside of the family. Since the 1920s, popular media has documented various social anxieties around babysitting and babysitters (Forman-Brunell, 2009), such as worries about them ruining marriages or overusing employers' belongings (Forman-Brunell, 2009). Research on babysitters generally groups them with other young workers, and reports on these experiences collectively (e.g. Raby et al., 2018; BesenCassino, 2018; Hungerland et al., 2007; Windau \& Meyer, 2005; Zierold et al., 2004), or is a part of a small body of older literature, some of which focuses on babysitting as preparation for parenthood (e.g. Kourany et al., 1980a, Kourany et al., 1980b, Kourany et al. 1986). However, some research on young workers excludes babysitting as work (MacLennan et al. 1985, Pond and Searle, 1991 - as cited in Morrow, 2008).

The experiences highlighted in this paper are drawn from a larger study of young people's first jobs in Ontario and British Columbia, Canada. Through three themes, we add to knowledge of babysitters and babysitting by analyzing babysitters' accounts of their jobs through the lenses of liminality and, following researchers such as Besen-Cassino (2018) and Kooreman (2009), gender inequality. First, while often considered an unskilled activity, our participants discussed babysitting as a skilled job that many had prepared for through formal and informal training. Second, babysitters shifted between adult and child positions as they navigated the liminal space between childhood and adulthood in their relationships with their employers and the children they cared for. Finally, the participants negotiated wages and were sensitive to the nuances of pay, although sometimes they faced challenges in this process.

\section{Literature Review}

The literature on babysitting is relatively sparse and predominantly American. There is some general research around young people's work which includes babysitters (e.g. Raby et al., 2018; Hungerland et al., 2007; Windau \& Meyer, 2005; Zierold et al., 2004), and some older articles which discuss more concrete aspects of babysitting (e.g. Kourany et al., 1980a; Kourany et al., 1980b) such as health and safety and meanings of work for young people. Two recently published books examine babysitting more closely - one on the history of babysitting (FormanBrunell, 2009), and one on babysitting and the gender wage gap (Besen-Cassino, 2018).

Forman-Brunell's (2009) book describes how, throughout the $20^{\text {th }}$ century, babysitters struggled with tensions between becoming independent participants in an ever-growing girlculture, which the wages from babysitting allowed, and parents' concern that this culture was a threat to girls' propriety and responsibility. Babysitting was thus tied to ideas about what teenage girls should be, and cultural anxieties linking their wages with consumerism and independence. Adult concerns about girls' independence were particularly prevalent in the 1920s and 1930s, which led many parents to prefer hiring boys as babysitters, even though most babysitters were girls (Forman-Brunell, 2009). Indeed, at various points throughout the $20^{\text {th }}$ century, boy babysitters being seen as more professional, intelligent and refined than girl babysitters (FormanBrunell, 2009). During the second half of the $20^{\text {th }}$ century, parents worried about girls' irresponsibility while babysitting - e.g. that they might spend all night on the phone, or neglect 
the children they were watching; such worries led to regulatory stories for babysitters through popular culture and formalized babysitter training courses (Forman-Brunell, 2009).

Throughout the $20^{\text {th }}$ century there have been concerns from babysitters themselves about their working conditions (Forman-Brunell, 2009). Young people interviewed for BesenCassino's book, The Cost of Being a Girl (2018), discuss how low wages and unpaid responsibilities were part of their babysitting experiences. Besen-Cassino also explores how babysitters often get their jobs through informal networks and extended family, placing babysitters in a difficult position when asking for better working conditions or remuneration, or if they want to quit, because they are seen as doing this work out of a loving connection to the children. Ironically, this emotional involvement can then be used to justify lower wages as caring for children is seen as natural for women (Needleman \& Nelson, 1988). In contrast, young men may more easily leave their babysitting jobs for relatively secure, higher status formal work as parents view boy babysitters' relationships with children as more professional and distant (Besen-Cassino, 2018; see also Kooreman, 2009 on early origins of the gender wage gap). Finally, young men seem to be held to fewer standards when babysitting. For example, the young women Besen-Cassino (2018) interviewed indicated the importance of their credentials (such as first aid and lifeguarding) for getting jobs as babysitters, whereas the young men were not required to have such credentials.

Apart from Forman-Brunell (2009) and Besen-Cassino (2018), there is surprisingly little research specifically on babysitters and their experiences. It is important to recognize why this gap in the literature might exist. Young people, and the jobs they engage in, are often undervalued and unrecognized (Mizen et al., 1999). Occupying a liminal position, young people are largely invisible as workers, with little data even collected on their experiences (Hobbs et al., 2007; Hungerland et al., 2007). For instance, in Ontario and British Columbia, where our young workers resided, governments do not collect data on workers under 15, or for jobs usually considered part of the informal economy (e.g. babysitting) ${ }^{1}$. When young workers are visible, their jobs are often seen as 'natural' for them to engage in (Hobbs et al., 2007) because they are part-time, low-skilled, and often gendered. Further, the work they do is in-between, or liminal work, because it is frequently informal (Hobbs et al., 2007). Finally, young people's work is not often considered work within more affluent societies because, as highlighted by Hungerland et al. (2007), it is not seen as providing a substantial portion of a family's income. Kourany et al. (1986) argue, however, that babysitting is one of the earliest examples of "paid labor undertaken by teenagers in a concerted, agreement-like, contractual manner with the adult world" (p. 199).

Combining the devaluation of young workers with the devaluation of work in childcare, as in the case of babysitting, creates added complexity. As outlined above, care-work is feminized and thus assumed to be unskilled, and therefore undervalued (Besen-Cassino, 2018; Grimshaw \& Rubery, 2007; Nelson \& Needleman, 1988). These age and gender-based inequalities may help to explain why there has been a lack of focus on babysitting in academia, and why it is often unrecognized in articles discussing other types of early work.

\section{Theoretical Positioning}

We take the constructionist position that childhood and adulthood are social, contextually located, shifting, hierarchical, intersected, and material. In many societies, current constructions of childhood and adulthood are understood in relation to work. Childhood is frequently associated with dependence, playfulness, and learning outside of work or work-like responsibilities, while adulthood is associated with responsibility, independence and work. 
Babysitting illustrates how such distinctions are problematic and persistently relevant. To talk about this in-between-ness of babysitting and babysitters, we draw on the concept of liminality.

Victor Turner explains liminality as being in between states or cultural classifications, and thus as an incomplete or elusive place that is distinct from both the previous phase and what is coming next. As he explains, "liminal entities are neither here nor there; they are betwixt and between" (1969:95). Liminality is thus "a moment in and out of time... and secular structure" (Turner 1969, p.96). Turner sees such a status as linked to social invisibility, but it can also be a sacred status, and hold potential for challenge or disruption. Some scholars have looked at young people's lives through this concept. For instance, Kevina Cody (2012) and Cody et al. (2011), have drawn on Turner's approach to liminality to look at tween girls' consumption practices. Cody and her colleagues see very young teens as in between the categories of child and teenager but located in neither. Tweens are thus positioned as incomplete and living in a "shadowed reality" (Cody et al., 2011: 385), which shapes their identity and consumption practices as their choices feel self-conscious and meaningful, yet also invisible. Cody (2012) thus argues that tweens' consumption practices are a way to manage their liminality.

The concept of liminality also resonates with Lesko's theorizing of adolescence (2001) as a constructed, pivotal, social time that is fraught because it is panoptic: for teenagers, their inbetween age is used as a lens to judge their actions, and teenagers are both positioned as "waiting passively for the future" (123) and expected to act as if "each moment of the present is consequential" (107). A focus on children and teenagers only in terms of their development or socialization into the future supports their preparation for later roles, including work roles, yet overlooks young lives - and work - in the present, and positions them in an excluded space in which they are unable to fully know or represent themselves (Lesko, 2001).

We have been drawn to the idea of liminality as a way to think about our data on young people's babysitting. While not sacred, or completely separate from child and adult roles and rituals in the way that Turner describes (1969), our participants were located between normative ideas about childhood and adulthood. Babysitting itself can be considered a liminal activity as it is neither play, nor what many problematically consider to be 'real work', largely because of its location as young, predominantly feminine, care work. In this paper we thus focus on how young people working as babysitters navigate this liminal, marginal location.

Gender inequality is also an important aspect and experience of babysitting work that is reflected in much of the current literature on babysitting and informs our analysis (Sheppard et al., 2019). Feminists have long noted that work traditionally associated with women is often taken for granted and inadequately remunerated (Grimshaw \& Rubery, 2007; Huppatz, 2009; Needleman \& Nelson, 1988). A key form of such feminized work is care-work. While women can sometimes benefit from assumptions about feminine nurturing when seeking care-based employment, these advantages fall away when women pursue anything above an entry-level position (Huppatz, 2009), and this work is still undervalued and underpaid (Grimshaw \& Rubery, 2007). Additionally, the assumption that this work comes naturally to women and girls devalues the preparation and skill needed for these positions (Besen-Cassino, 2018). Often, care-work is not even considered work at all (Neeleman \& Nelson, 1988). These gendered patterns that undermine care-work are reflected in the literature on babysitting. Further, we cannot talk about babysitting without also noting that it is primarily girls who babysit; and boys who babysit often explain their activities within these gendered assumptions and inequalities (Sheppard et al., 2019) 


\section{Methods}

This research project consisted of interviews with 32 young people in Canada: twentythree participants were from two cities in Ontario and nine were from British Columbia. After institutional ethics board review at two universities, participants were located through advertising and snow-ball sampling, asking young people to participate in interviews about their "first jobs." We did not explicitly call for babysitters but found that many of the young people interviewed had worked as babysitters. Notably, some participants who had babysat, and were now working in another job, did not count babysitting as their "first job." All participants were between the ages of 11 and 17, although the majority were under 16. Most participants were white and of varying economic backgrounds. For this paper, only interviews with participants who said they had engaged in babysitting at some point were analyzed, for a final sample of 16 participants (see Table 1). As is true for other researchers (e.g. Forman-Brunell, 2009; Besen-Cassino, 2018), our sample of babysitters was predominantly young women (13 out of 16). The interviews were open-ended and in-depth, loosely following an interview guide that included questions about what kinds of paid work participants had done, what their tasks involved, how much they were paid, how they negotiated pay, what they did with their earnings and whether their early work shifted their relationships with parents, teachers and/or peers. All participants were also invited to participate in a follow up, photo-elicitation interview to learn more about their jobs. Twelve participants, six of whom had worked as babysitters, did so (see Raby et al., 2018).

After the interviews, audio recordings were transcribed verbatim. All transcripts from individuals who had worked as babysitters were coded descriptively, with a focus on moments when participants discussed their babysitting. Interview excerpts related to babysitting were then collected together based on their descriptive codes, and then compared and coded systematically and analytically by two of the authors to identify shared themes amongst babysitters' interviews. Emergent themes were then reviewed and discussed by the whole research team. All references to real people or places, including the names of our babysitters, were replaced with pseudonyms. Participants were able to choose their own pseudonym.

The babysitters we interviewed described how they got their jobs, their day-to-day experiences in their jobs, the preparation and training they engaged in to do their work, their relationships with the children they babysat, and how their wages were negotiated. Many found their jobs through family or neighbourhood connections, similar to previous research (e.g. Besen-Cassino, 2018). The participants' jobs ranged from all-day babysitting for weeks during the summer to occasionally babysitting for families on weekends. In this paper, we discuss three themes from our analysis. As part of this discussion, we highlight how babysitters exist in an inbetween and gendered space, navigating and occupying different roles, identities and expectations related to childhood, teenagehood and adulthood, depending on their context.

\section{Preparation for babysitting}

While babysitting is generally considered unskilled work, like Besen-Cassino (2002), we found some babysitters gain prior experience through formal training and practical experience, including caring for younger siblings. Our young workers invested a lot of unrecognized or unremunerated time, and often money, into preparing for babysitting. Many of our young workers had taken a babysitting course or had some other form of formal training, such as life guarding, first aid training, or a "home alone" course ${ }^{2}$. For instance, Rose commented that she was glad she had first aid training because it helped her when a child she was watching started choking. Other participants spoke to informal training which made them feel well prepared for 
their jobs. For example, Taylor explained why she did not take a formal babysitting course: "I didn't really feel like I needed to do that because I'm just around kids all the time cuz my mom does daycare." For Taylor, previous experience caring for children in her mom's daycare provided her with the skills and experience she felt she needed to babysit on her own. This formal and informal preparation for babysitting seemed to also help parents feel confident in their abilities, and likely cemented their positions. For instance, Emma indicated that the people she babysat for wanted someone who was comfortable around pools, and her lifesaving qualifications helped her get the job.

Many babysitters also spoke about their preparation for work. Taylor spoke about researching different craft ideas online, switching books and games to keep the children she watched engaged and interested, and otherwise structuring the day so that the children were kept occupied. Other babysitters, particularly those who babysat for full days in the summer talked about planning at least a few activities for each day. For our babysitters this planning happened outside of their working hours, without remuneration. Many babysitters also developed elaborate games. For example, Mia described the intricacies of creating indoor Nerf-gun obstacle courses with the boy she babysat:

... we took the couch and we took the cushions off, and we built this little like tunnel through the living room? [...] you had to like kind of like slither through them, like crawl, but you couldn't even really crawl cuz they were so small [...] and in between each crack um, somebody was trying to get you, like trying to shoot you...

In this example, Mia actively engaged with the boy she babysat to develop an activity that they could do together. Not only did this help Mia bond with him, it also shows the thought she put into organizing games while babysitting. Later in the interview, Mia talked about how she used her academic skills to tutor one of the other children she babysat.

Additionally, many babysitters used a lot of 'soft' or 'people' skills on the job - such as negotiation. Babysitting may be seen as a stepping-stone to other jobs, but often without recognition of the skills gained from babysitting. Some of our babysitters even talked about their hopes that they would be able to get a 'real' job once they were old enough. For example, some of our babysitters encountered challenging situations which tested their skills. Mia discussed how she addressed questions and issues of inequality and death with the children she babysat:

It's kind of hard sometimes to answer some of their questions [...] he has asked me, especially when we were reading [...] [The Titanic], about you know, like why, why did the third class people, why did so many of them die, like why didn't people try to help them? [...] questions like that, they're so simple for the children, but like, you know it's kind of like, makes you kind of disappointed in humans sometimes [...] You're kind of like, uh, I don't want to destroy your innocence here [...] I just told him that you know, sometimes people think that they're um, higher up, better than others, and they believe that they should be saved before other people [...] he asked me like "Why... why did they think they're better than other people?" and I said "well, it might be because of money, because [...] like, you know, in older days, even now really, their family names sometimes are better than others, more money, where they live, stuff like that, and he just kind of said "oh, okay" and he just moved on to the next topic... In this situation Mia sensitively negotiated the expectations of her employer, her relationship with the young boy she was babysitting, and her personal beliefs about how best to address the situation. Mia also drew on her knowledge of child development to provide him with information that he would understand and find meaningful without upsetting him. Other babysitters, such as 
Bob, talked about how they carefully negotiated with children and were skilled at preventing fights between siblings:

I usually give them like fifteen minutes. I say 'you have to brush your teeth, get dressed, pick out your three books, be in bed...' and if they do that, they get like two extra books, but if they don't do that then they get like one less book.

Bob's system helped him prevent fights between the children he babysat, and also helped him to ensure a smooth bedtime transition.

Many young people invest time and energy into babysitting well. A component of liminality, as described above, is an invisibility that comes with being outside of established, formal identities or structures. We are arguing that babysitting and babysitters are in such a liminal location. Babysitting work is skilled work that many have trained for, and yet is rarely counted, valued or studied as work, partially because it is informal and because of the gendered assumption that these skills are natural (Besen-Cassino, 2018). The stories we were told by our young workers contradict common discourses about babysitters being lazy or naturally good at their jobs (e.g. because they are girls), instead highlighting the training, investment, and skill that helped them to be successful. These accounts demonstrate the skill and investment required for babysitting, something that other researchers working with young people need to consider, especially as babysitting is generally not considered substantial work (Hungerland et al., 2007).

\section{Childhood, Adulthood, and Babysitters' Relationships}

Our second theme looks at how these young workers were engaged in negotiations around being children and/or adults, both with their employers and the children they babysat. Rather than being outside of the categories of child and adult, babysitters seemed to shift between them and exist in an in-between space, depending on the context of the situation they were in. Participants themselves seemed divided on whether they were more like children, for instance playing with the children they were babysitting, or if they were more like adults, e.g. by being in control - comments which reinforced normative categories of child and adult. For example, Billy discussed how choosing to act more like a child or an adult required some internal negotiation, between being a child's friend, and being an adult in charge:

I try to like be calm about it [...] try to like, nonchalantly just mention, "oh, leave it, you have to go to bed now," or "you have to eat dinner." And if then they start to ignore me or just make excuses not to, then I'll start to get stern with it but I really don't like it much because I don't really want to like be that kind of person that they don't like. In contrast, Billy's older brother Ginger enjoyed being a leader with the children: "you have the leadership role which is kind of, it can be fun, when you have to like, when they look up to you," although he also spoke about how he enjoyed this until he had to discipline the children. Hungerland et al. (2007) found that for young babysitters, taking on extra responsibilities feels like "transcend[ing] the childhood space of play to which they have been ascribed" (p. 265), and bringing more adult status, but both Billy and Ginger suggest that they must navigate a more inbetween space. Employers also contributed to the liminality of babysitters by simultaneously holding views of them as mature and responsible, and as more child-like by deciding their wages or viewing them as having less status due to age. Mia described some of this complexity: "[my employers] treat me more... as an adult than my parents sometimes, but also they also treat me like... a kid, because they do know I'm only fourteen, well twelve when I started."

Besen-Cassino (2018) has similarly reported that the young women she interviewed interacted with parents and children differently when babysitting. For example, one participant 
mentioned the "often-clashing expectations to appear polished, responsible, and dependable for the parents and fun and cool for the children" (Besen-Cassino, 2018, p. 51). Managing both a more adult persona, such as being responsible and dependable, along with a more child-like persona, such as being fun and cool, were ideas that our babysitters spoke about. Liminality has been linked to teenagehood more generally, but it takes on a specific set of challenges when young people are working with children, as one of their potential advantages (being child-like) is also one of their liabilities as workers.

With our young workers, liminality seemed to offer both opportunities and challenges. For example, adapting one's presentation based on interaction with either parents or children can be a useful skill as babysitters can demonstrate they are capable of being both responsible and fun. Additionally, it affords participants opportunities for employment with children of differing interests and personalities, as babysitters' flexibility and adaptability can be used to best suit the needs of the children they are watching. However, there are also challenges with existing in a space in which someone is not quite a child and not quite an adult - or where they feel like both an adult and a child. Some parents may be extra concerned about having younger babysitters, for instance, or may under or overestimate their capacities. On the job, babysitters also may not be taken as seriously in situations where they need to be. This happened to Mia when the boy she babysat wanted to use a homemade zipline with a coat hanger and a rope in his backyard.

...well I told him it wasn't a good idea, and then he said "it'll be fine, I did it with my dad" and, he showed me a video his sister took of it, so I was like "okay, well [...] If he's done it with his dad then that's okay." So then he did it, and as he, like he brought it out, the coat hanger, and it was really bent, and I was like "no, no, we're not doing this" and then he did it anyways, and, it just kind of snapped halfway down...

Although the boy was okay, Mia described this as a scary experience. In this situation, Mia may have felt that she could not be as authoritative as necessary because she was young and wanted the child to have fun with her as a babysitter.

Forging relationships with children was also about drawing on assumed shared, normative gendered interests, especially for boy babysitters. Bob seemed to feel that his gender made him the best choice to babysit boys because of a shared love of sports. He explained that the boys he babysat "... get along with them [girl babysitters], but they like having a boy [babysitter]... cuz I like to, [I] like, playing sports with them." In contrast, when describing how gendered interests might affect Taylor's relationship with the children she babysat, she said that although the boys she babysat played with different toys, they shared commonalities related to childhood, "Well I wasn't a truck and dinosaur person [...] but I liked dolls and like the My Little Ponies, so in a way it was kind of like make-believe in your head almost, so kind of [the] same concept." For Taylor, her childhood was a stronger link to the children she babysat than her gender.

By uniquely examining this early work through the lens of liminality, we draw attention to the positioning of young workers, and how their age can be both a liability and an asset. We illustrate how babysitters navigate this liminality in their work, e.g. by being leaders with children but also drawing on their child-like attributes to be seen as desirable babysitters. These babysitters demonstrate the nuances of working in a job situated between childhood and adulthood, and the need to consider how this impacts work-related relationships with both children and parents.

\section{Negotiating Pay}


Liminality can be challenging when babysitters try to negotiate pay with employers, especially in the gendered and informal context of babysitting. Besen-Cassino (2018) discusses how babysitters' work is generally undervalued and poorly remunerated. Babysitting is also often informal, casual work outside of minimum wage legislation. The young people we interviewed talked about negotiating wages with parents/employers, and these stories provide further evidence of participants' liminal and precarious location - between being young helpers going along with whatever parents decide and independent entrepreneurs setting their own wages. In our interviews, babysitters often agreed to whatever wage parents decided - generally less than minimum wage, at $\$ 5$ to $\$ 11$ Canadian per hour. Given that most babysitters are girls or young women, babysitter pay arguably begins the gender wage gap (Besen-Cassino, 2018; Lintonen et al., 2016; Kooreman, 2009).

For most of the young people we interviewed, pay depended on how many children they babysat, as well as when they worked (e.g. evenings versus all day). Some participants, like Mariah and Taylor, said they just accepted whatever the parents offered. Mariah suggested that this was fine because for her, babysitting is fun. In contrast, Emma accepted the pay that was offered, even if she did not think it was fair, because she knew her employers would opt for a cheaper babysitter if she asked for more.

However, in contrast to participants like Mariah, Taylor and Emma, and the participants in Besen-Cassino's work who had difficulty negotiating wages (2018), others in our study told their employers an expected wage. Some based their expectations on what they knew other babysitters earned and their own skills. Mia also consulted with her mom:

At first I was thinking more around like... \$8? [...] my friend actually charges $\$ 10$ an hour, which I think is a little much, just because, like I said before, not everybody has that type of money, um, but my mom said when she was younger and she used to babysit, it was around $\$ 5$ an hour, but that I'm more experienced and I'm able to do more stuff with the kids, so that we could put the price up a little more? Um, so we decided $\$ 7$ was kind of in between ten and uh, five, and it was a fair price.

Olivia negotiated her pay with parents of the children she babysat based on what they could afford, and her expected duties:

There's some families that like, obviously they can't afford $\$ 10$ an hour if it's like five hours like, and that's fine [...] if the kids are asleep in that time period, like it's not that big of a deal cuz I'm not doing anything anyways [...] but definitely during the day when there's two kids and I'm constantly, constantly having to find something to do, make sure they're out of trouble [...] \$10 I mean seems pretty reasonable.

Olivia downplayed the work she does when the children are asleep, and said she would agree to babysit if a family needed her, even if they could not afford $\$ 10$ an hour, otherwise she would feel bad. Other participants suggested their initial wage based on what other babysitters were charging. As Emma explained, our babysitter used to ask for that much [ $\$ 10$ per hour] $(\mathrm{mhm})$ and then since there's three kids that I babysit, I still ask for ten cuz I know that [...] our [babysitting] neighbours are just gonna ask [for] the same amount if they want to babysit.

As an in-between position, Charlotte described how she carefully considered what she should be paid, but still ultimately left the decision up to the employer: "I usually tell them they can choose [how much to pay] but they still want something so I usually just take an average of like what other people have normally paid me in the past and just tell them that." Overall, about half of our sample had a say in what they were paid. 
While Saari et al. (2017) similarly found that about half of young people negotiated their wage for a variety of paid jobs and informal chores, very few expected their employers to set a wage which they would then negotiate higher, even though that could be considered the norm for many adult workers. Besen-Cassino (2018) also found that the young women she talked to rarely asked their babysitting employers for raises because personal ties made it challenging. In our study, Michelle similarly highlighted how personal ties meant lower wages: “... well sometimes I'd babysit my little cousins but I wouldn't get paid as much as I get paid now [for babysitting other people]. Like, I'd get paid like half of it cuz they're [extended] family so I'm like 'okay, whatever." In our study, only Rose explicitly asked for, and was successful in getting, a raise. She negotiated her pay up from $\$ 8$ to $\$ 11$ per hour because she babysat for a family with four children under the age of eight and they were "a handful."

Saari et al. (2017) found that even though few young people negotiated a raise, when they did so, their experiences were either neutral or positive, and their wage outcomes were closer to what they wanted. However, there can be gender-based challenges when young people ask for raises. In a hypothetical research scenario, Besen-Cassino (2018) found that parents supported boy babysitters more than girl babysitters when they asked for a raise, especially when parents thought that young women had an emotional connection with their child. However, boys without an emotional connection were the most likely to receive a raise (Besen-Cassino, 2018). This highlights the challenges for when asking for a raise, and how the perceived naturalness of an emotional connection can lead to the undervaluing of girls' care work. Encouraging young people to negotiate for raises is thus important to help young people - especially girls - to advocate for themselves and the fair remuneration of their work, even though this can be tricky based on their liminality and the gender-based challenges above.

In their negotiations of pay, young people sometimes challenged dominant notions of babysitters as being unskilled, accepting of adult decisions, or otherwise childlike. In contrast with previous research, many of our participants had a say in their wage, establishing pay that was consistent with other babysitters' rates and that they felt was appropriate. It could thus be argued that in these situations, babysitters were occupying a more entrepreneurial, independent and adult-like role. However, the norms for appropriate and expected pay were generally low, and about half of our sample let employers decide their wages. Again we see how babysitters exist in a liminal, in between, space that is linked to both their age and their location in precarious, gendered, informal work. This liminal location brings a certain degree of flexibility in negotiating wages that is not present in workplaces that are formally governed by minimum wage laws, but also brings low wages, vulnerability to the desires and generosity of employers, and vulnerability to gender discrimination. These findings highlight the importance of including babysitters when examining young workers' pay and recognizing the value of babysitting work.

\section{Conclusion}

We have highlighted babysitters' experiences and negotiations in their everyday work, drawing on liminality and the prevalence of gender inequality in order to capture some of the opportunities and challenges of being a young babysitter. Our paper directly addresses the undervaluing of babysitting, including popular and academic assumptions that babysitting is not 'real' work by highlighting our babysitters' preparation and skills. For example, our babysitters spent much unremunerated time preparing activities for the children they babysat. Additionally, the babysitters frequently pursued training and used many different skills for the job, while navigating nuanced aspects of their relationships with the children they babysat, and the 
complexities of negotiating their wages. We also illustrate how gender inequality has been used to marginalize babysitters, for example through the idea that girls are babysitting out of love for the children instead of considering it a valid form of paid employment.

Liminality is a concept that arises only occasionally in child and youth studies and yet our study suggests that it can be a useful conceptual tool. For our babysitters, instead of being a position of exclusion or resistance, liminality allowed for flexibility and strategy, such as using adult-like authority when negotiating wages, but foregrounding playfulness as a babysitting skill. Our babysitters thus mobilized their liminality in forging relationships with employers and the children they babysat. Examining liminality with other babysitters is an area for future research, although in discussing liminality, we became concerned that we were reproducing narrow, normative conceptualizations of childhood and adulthood.

One limitation of this research is that we did not explicitly set out to interview babysitters when conducting our research into young people's first jobs. Our interviews were open-ended, with questions adapted to the context of the participants' specific jobs, including babysitting. When analyzing our data, we found that babysitters' experiences were worthy of focus, but further research concentrated only on babysitting is needed. For instance, while our paper has demonstrated that babysitting needs to be taken seriously as a form of work, a longitudinal project following babysitters' experiences, including why they babysit and whether (and how) they transition into other work, is needed. A second limitation is the lack of diversity in our sample. A more inclusive, intersectional approach to the study of babysitting, exploring interactions of race, class, gender, disability and sexuality in babysitters' experiences is vital. A more diverse sample could illustrate how inequality plays out in babysitting, including how some young people are afforded greater opportunity to use their liminality to their advantage than others. Besen-Cassino explores intersections of gender, race and class through a diverse, mixedmethod sample in her research on young people's early work (2008), finding that many employers in formal part-time jobs, such as those in retail, favour affluent, white workers. She also touches on these intersections in her later book that includes a more direct examination of participants reflecting on babysitting in their pasts (2018), finding that racialized girls were more likely to stay in babysitting for longer, in part because of familial connections to the jobs that make quitting challenging. Future work could follow Besen-Casino's analysis but speak directly to such intersectionality (see Crenshaw, 1989) in the immediate lives of babysitters.

Overall, examining babysitters' experiences provides broader insight into why and when young people start informal work, their experiences with early work, and the relevance of intersectional inequities. Comprehensive, specific research on babysitting helps to advance our understanding of young people's employment experiences. 


\section{References}

Besen-Cassino Y (2008) The cost of being a girl: Gender earning differentials in the early labor markets. NWSA Journal, 20(1): 126-160.

Besen-Cassino Y (2018) The cost of being a girl: Working teens and the origins of the gender wage gap. Philadelphia, PA: Temple University Press.

British Columbia Employment Standards Act, RSBC [1996, c. 113]. Retrieved from http://www.bclaws.ca/civix/document/id/consol22/consol22/00 9611301

Cody K (2012) 'BeTween two worlds': Critically exploring marketing segmentation and liminal consumers. Young Consumers, 13(3): 284-302.

Cody K, Lawlor K and Maclaran P (2011) On the borderline: Metaconsumption and the liminal tween. European Advances in Consumer Research, 9: 385-393.

Crenshaw K (1989) Demarginalizing the intersection of race and sex: A black feminist critique of antidiscrimination doctrine, feminist theory and antiracist politics. $u$. Chi. Legalf., 139.

Forman-Brunell M (2009) Babysitter: An American history. New York, NY: New York University Press

Grimshaw D and Rubery J (2007) Undervaluing women's work. Manchester: Equal Opportunities Commission.

Hobbs S, McKechnie J and Anderson S (2007) Making child employment in Britain more visible. Critical Social Policy, 27(3): 415-425.

Huppatz K (2009) Reworking Bourdieu's 'Capital': Feminine and female capitals in the field of paid caring work. Sociology, 43(1): 45-66. doi: 10.1177/0038038508099097

Hungerland B, Liebel M, Liesecke A and Wihstutz A (2007) Paths to participatory autonomy: The meanings of work for children in Germany. Childhood, 14(2): 257-277.

Kooreman P (2009) The early inception of labor market gender differences. Labour Economics, 16: $135-139$.

Kourany RF, Gwinn M and Martin JE (1980a) Adolescent babysitting: A 30-year-old phenomenon. Adolescence.

Kourany RF, Martin JE and LaBarbera JD (1980b) Adolescents as babysitters. Adolescence.

Kourany RFC and LaBarbera JD (1986) Babysitting: A Milestone of Early Adolescence. Journal of Early Adolescence, 6(2): 197-200.

Lesko, N (2001) Act Your Age: A Cultural Construction of Adolescence. New York: RoutledgeFalmer.

Lintonen TP, Wilska TA, Koivusilta LK and Konu AI (2007) Trends in disposable income among teenage boys and girls in Finland from 1977 to 2003. International Journal of Consumer Studies, 31(4): 340-348.

Mizen P, Bolton A and Pole C (1999) School age workers: The paid employment of children in Britain. Work, Employment and Society, 13(3): 423-438. doi: $10.1177 / 09500179922118015$

Morrow, V (2008) Chapter 6: Responsible children and children's responsibilities? Sibling caretaking and babysitting by school-age children in Responsibility, Law and the Family eds. Bridgeman J, Keating H, and Lind C. Routledge, New York, N.Y., United States.

Needleman R and Nelson A (1988) Chapter 16: Policy Implications: The Worth of Women's Work in The Worth of Women's Work: A Qualitative Synthesis eds. Statham, A., Miller, E. M., \& Mauksch, H. O. State University of New York Press, Albany, N.Y., United States. 
Ontario Occupational Health and Safety Act, R.S.O [1990, c. O.1] Retrieved from https://www.ontario.ca/laws/statute/90o01/v27

Raby R, Lehman W, Easterbrook R and Helleiner J (2018) "I'll Be More Prepared Than Most People": Very Young Canadian Workers Talking About Their First Jobs. Childhood, 1-16.

Saari ML, Wood E and Wood K (2017) Work, Remuneration, and Negotiation for Pay in Early Adolescence: Exploring Early Causes of Gender Pay Inequity. Journal of Financial Counseling and Planning, 28(1): 20.

Sheppard LC, Raby R, Lehmann, W and Easterbrook R (2019) Grill Guys and Drive-Thru Girls: Discourses of Gender in Young People's Park-Time Work. Journal of Childhood Studies, 44(3): 56-69.

Turner V (1969) The ritual process: Structure and anti-structure. Chicago: Aldine Pub. Co. Windau J and Meyer S (2005) Occupational injuries among young workers. Monthly Labor Review, 128, 11.

Zierold KM, Garman S and Anderson H (2004) Summer work and injury among middle school students, aged 10-14 years. Occupational and Environmental Medicine, 61(6): 518-522. 
Table 1: Interview participants

\begin{tabular}{|l|l|l|}
\hline City \#1 in Ontario & Age & Work \\
\hline 1) Angela & 15 & Babysitting; ice cream store \\
\hline 2) Michelle & 16 & Babysitting; drug store; fast food \\
\hline 3) Ginger & 16 & Babysitting; studio hand \\
\hline 4) Billy Pilgrim & 14 & Babysitting \\
\hline 5) Taylor & 14 & Babysitting; newspaper delivery \\
\hline 6) Charlotte & 16 & $\begin{array}{l}\text { Babysitting; newspaper delivery; fast } \\
\text { food }\end{array}$ \\
\hline 7) Mariah & 16 & Babysitting; fast food \\
\hline 8) Olivia & 16 & Babysitting; dishwasher; pumpkin patch \\
\hline
\end{tabular}

\begin{tabular}{|l|l|l|}
\hline City \#2 in Ontario & Age & Work \\
\hline 1) Emma & 14 & Babysitting \\
\hline 2) Mia & 14 & Babysitting \\
\hline 3) Patricia & 12 & Babysitting; day camp volunteer \\
\hline 4) Bob & 14 & Babysitting; odd jobs \\
\hline 5) April & 13 & Babysitting \\
\hline 6) Violet & 16 & Babysitting \\
\hline
\end{tabular}

\begin{tabular}{|l|l|l|}
\hline City in British Columbia & Age & Work \\
\hline 1) Rose & 14 & Babysitting; house cleaning \\
\hline 2) Jane & 17 & $\begin{array}{l}\text { Babysitting; lemonade stand; newspaper } \\
\text { delivery; restaurant; unionized retail }\end{array}$ \\
\hline
\end{tabular}

\footnotetext{
${ }^{1}$ At the time of this research, young people needed to be 14 in Ontario and 15 in British Columbia to work in formal settings (British Columbia Employment Standards Act, 2011; Ontario Occupational Health and Safety Act, 2016). In British Columbia, those between 12 and 14 could work in formal settings, for limited hours, with parental permission. Children under 12 could work if given permission by their parent(s), their school, and the Director of Employment Standards (British Columbia Employment Standards Act, 2011). In Ontario, there were other restrictions for certain kinds of work, e.g. in a kitchen (minimum age of 15) or construction (minimum age of 16) (Ontario Occupational Health and Safety Act, 2016).

${ }^{2}$ Similar to babysitting courses, there are a variety of "home alone" courses in Canada, giving children skills to prepare them to stay home alone.
} 